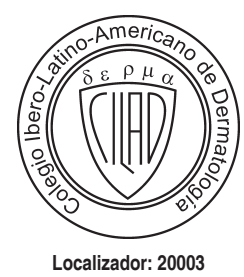

doi: $10.35366 / 91768$

\title{
Deposite su diagnóstico
}

\author{
Deposit your diagnosis
}

Antonio José Durán Romero, ${ }^{*}$ Mercedes Sendín Martín,*

Javier Mohigefer Barrera, ${ }^{\dagger}$ Inés De Alba Rioja, ${ }^{\S}$ Julián Conejo-Mir Sánchez

\section{HISTORIA CLÍNICA}

$M$ ujer española de 54 años, sin antecedentes de interés, que consulta por enrojecimiento y pérdida de elasticidad cutáneos de forma

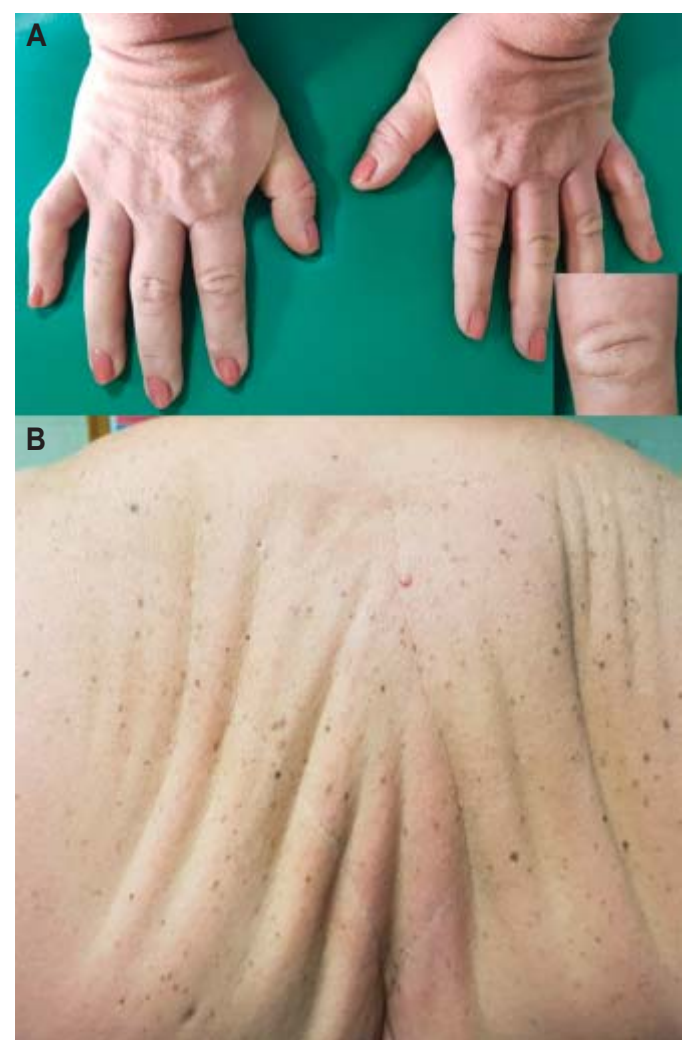

Figura 1: A) Dorso de articulaciones interfalángicas con el signo «donut» o signo de la rosquilla. B) Acentuación de pliegues cutáneos de la espalda con la retracción escapular dando lugar al signo de Shar-Pei. difusa en los últimos cuatro meses. Asimismo, refería dificultad para la movilización de los miembros superiores, sin dolor asociado. No clínica infecciosa o ingesta de fármacos en relación al cuadro. ¿Cuál es el diagnóstico más probable?

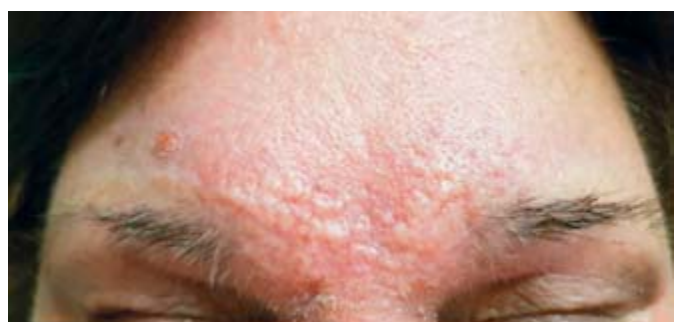

Figura 2: Pápulas induradas agrupadas en región glabelar, algunas con disposición lineal.

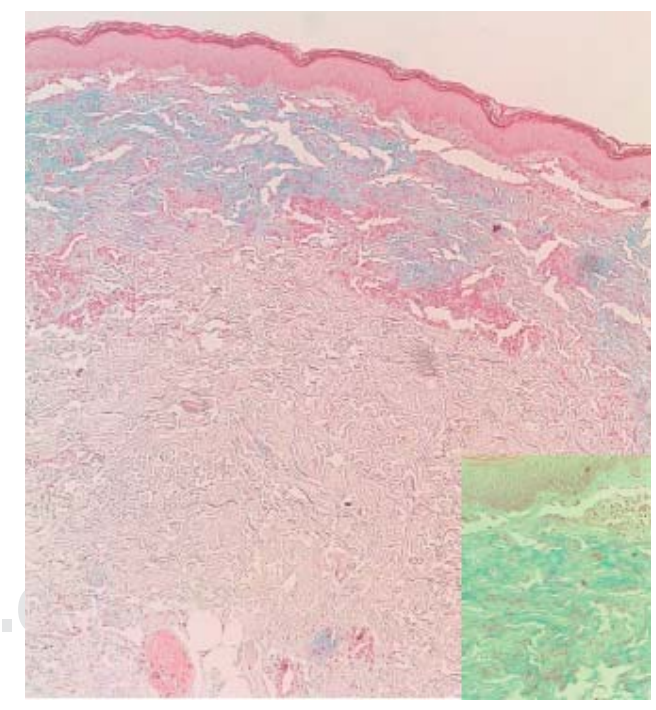

Figura 3: Depósito dérmico intersticial de mucina (azul-alcián positiva), aumento discreto de fibras de colágeno e incremento de la celularidad a expensas de fibroblastos. 


\section{DIAGNÓSTICO}

En la exploración clínica destacan la marcada acentuación de los pliegues cutáneos, tanto en el dorso de las articulaciones falángicas (Figura 1A) como en la región superior de la espalda (Figura 1B). Además, se apreciaba un engrosamiento cutáneo generalizado a la palpación, con notable pérdida de elasticidad, y la presencia de múltiples pápulas induradas en región glabelar (Figura 2), algunas con distribución lineal. No se observaron lesiones en mucosas.

La biopsia cutánea mostró un infiltrado dérmico intersticial de mucina (Figura 3), discreto incremento de fibras de colágeno y aumento de la celularidad a expensas de fibroblastos.

Se realizó una analítica completa donde se objetivó un aumento de IgG Kappa, de tipo monoclonal. La biopsia de médula ósea confirmaría el diagnóstico de síndrome linfoproliferativo con gammapatía monoclonal lgG.

Considerando la clínica, histología y el síndrome linfoproliferativo asociado, llegamos al diagnóstico de escleromixedema.

El tratamiento con inmunoglobulinas intravenosas ha logrado mejoría parcial de las lesiones cutáneas y recuperación funcional completa en la paciente.

\section{COMENTARIO}

El escleromixedema es una mucinosis cutánea primaria que afecta a adultos de edad media, no existiendo predilección entre sexos. Clínicamente, se caracteriza por la erupción de pápulas induradas de distribución lineal y cambios esclerodermiformes en la piel circundante. ${ }^{1}$ La mayoría de casos se acompañan de gammapatía monoclonal (> 83\%), sin conocerse bien su papel etiopatogénico. ${ }^{2}$ El depósito dérmico de mucina, la proliferación de fibroblastos y la fibrosis conforman la tríada necesaria para su diagnóstico histológico..$^{1-3} \mathrm{El}$ manejo del escleromixedema se basa en casos aislados o series de casos, siendo las IgIV el tratamiento de primera línea más aceptado. ${ }^{3}$

\section{BIBLIOGRAFÍA}

1. Rongioletti F, Rebora A. Updated classification of popular mucinosis, lichen myxedematosus, and scleromyxedema. J Am Acad Dermatol. 2001; 44 (2): 273-281.

2. Rongioletti F, Merlo G, Cinotti E, Fausti V, Cozzani E, Cribier B et al. Scleromyxedema: a multicenter study of characteristics, comorbidities, course, and therapy in 30 patients. J Am Acad Dermatol. 2013; 69 (1): 66-72.
3. Knobler R, Moinzadeh P, Hunzelmann N, Kreuter A, Cozzio $A$, Mouthon $L$ et al. European dermatology forum S1-guideline on the diagnosis and treatment of sclerosing diseases of the skin. Part 2: Scleromyxedema, scleredema and nephrogenic systemic fibrosis. J Eur Acad Dermatol Venereol. 2017; 31 (10): 1581-1594 